Hydrological Research Letters 5, 37-41 (2011)

Published online in J-STAGE (www.jstage.jst.go.jp/browse/HRL). DOI: 10.3178/HRL.5.37

\title{
Temporal and Spatial Discontinuity of Radar/Raingauge-Analyzed Precipitation That Appeared in Relation to the Modification of Its Spatial Resolution
}

\author{
Shinji Urita ${ }^{1}$, Hitoshi Saito ${ }^{1,2,3}$ and Hiroshi Matsuyama ${ }^{1}$ \\ ${ }^{1}$ Department of Geography, Graduate School of Urban Environmental Sciences, \\ Tokyo Metropolitan University, Tokyo, Japan \\ ${ }^{2}$ Present Affiliation: Center for Spatial Information Science, The University of Tokyo, Chiba, Japan \\ ${ }^{3}$ Research Fellow of Japan Society for the Promotion of Science, Tokyo, Japan
}

\begin{abstract}
:
To quantitatively evaluate how different methods for creating $5 \mathrm{~km}$ mesh Radar/Raingauge-Analyzed Precipitation (R/A) affected annual precipitation, we compared three kinds of $5 \mathrm{~km}$ mesh R/A during 1991-2009 by devoting attention to the modification of its spatial resolution. It was, respectively, $5 \mathrm{~km}$ until March 2001, $2.5 \mathrm{~km}$ from April 2001 to December 2005, and $1 \mathrm{~km}$ from January 2006. For creating $5 \mathrm{~km}$ mesh R/A, three methods were adopted, i.e., (I) spatial average of $2.5 \mathrm{~km}$ or $1 \mathrm{~km}$ mesh was calculated. (II) Maximum value of $2.5 \mathrm{~km}$ or $1 \mathrm{~km}$ mesh was selected. (III) For creating $2.5 \mathrm{~km}$ mesh from $1 \mathrm{~km}$ mesh, spatial average of $3 \times 31 \mathrm{~km}$ mesh was calculated considering the representative area of each mesh. For creating $5 \mathrm{~km}$ mesh from $2.5 \mathrm{~km}$ mesh, maximum value of four $2.5 \mathrm{~km}$ mesh was selected. The method III is suggested by JMA. We found abrupt changes of annual precipitation were seen in 2000/2001 (method I) and 2005/2006 (method II), both of which were artificial temporally and spatially compared with AMeDAS data. The $5 \mathrm{~km}$ mesh R/A created by the method III was statistically homogeneous, so we recommend that we should adopt the method III.
\end{abstract}

KEYWORDS Radar/Raingauge-Analyzed Precipitation (R/A); Automated Meteorological Data Acquisiton System (AMeDAS); spatial resolution; artificial discontinuity; homogeneity

\section{INTRODUCTION}

Radar/Raingauge-Analyzed Precipitation (R/A) provided by Japan Meteorological Agency (JMA) was developed to prevent rainfall-related disasters. This dataset has high accuracy for short-term intensive precipitation, although some discontinuities were reported if it was used for long-term analysis (e.g. Kamiguchi et al., 2010). These discontinuities are regarded to be derived from modification of the spatial resolution of $\mathrm{R} / \mathrm{A}$, change of the algorithm for creating $\mathrm{R} / \mathrm{A}$, and incorporation of precipitation data of local governments, and so on.

The spatial resolution of R/A was, respectively, $0.0625^{\circ}$

Correspondence to: Shinji Urita, Department of Geography, Graduate School of Urban Environmental Sciences, Tokyo Metropolitan University, 1-1, Minami-Ohsawa, Hachiouji, Tokyo 192-0397, Japan. E-mail: uritashinji@ed.tmu.ac.jp (C2011, Japan Society of Hydrology and Water Resources. (longitude) $\times 0.05^{\circ}$ (latitude; ca. $5 \mathrm{~km}$ ) until March 2001, ca. $2.5 \mathrm{~km}$ from April 2001 to December 2005, and ca. 1 $\mathrm{km}$ from January 2006 . To analyze the interannual variation for the whole period, we must create a dataset with $5 \mathrm{~km}$ resolution from April 2001. Especially, for calculating the Soil Water Index (Okada et al., 2001) which forecasts shallow landslide susceptibility, homogeneous long-term $\mathrm{R} / \mathrm{A}$ with $5 \mathrm{~km}$ resolution is necessary as input data (Okada, 2007).

In this regard, JMA advised the preparation of $5 \mathrm{~km}$ mesh R/A as follows (Nagata and Tsujimura, 2006, Figure 1, method III in the next section). (a) For creating $5 \mathrm{~km}$ mesh data from $2.5 \mathrm{~km}$ data, we should overlay these data and select the maximum value of four $2.5 \mathrm{~km}$ mesh data, and regard it as the representative value of the $5 \mathrm{~km}$ mesh. (b) For creating $2.5 \mathrm{~km}$ mesh data from $1 \mathrm{~km}$ data, we must overlay these data and calculate the spatial average of $3 \times 3$ $1 \mathrm{~km}$ meshes, considering the representative area of each mesh. Subsequently, we follow the method (a) above. Deshimaru et al. (2009) noted that without these procedures, some discontinuities would appear in the time series. However, previous studies (e.g., Kamiguchi et al., 2010; Tsuguchi and Kato, 2010) did not follow these procedures, which might have caused the abrupt changes of the interannual variation of R/A. Furthermore, no quantitative evaluation has been conducted yet concerning the procedures suggested by Nagata and Tsujimura (2006).

The objective of this study is to clarify how different methods for creating $5 \mathrm{~km}$ mesh $\mathrm{R} / \mathrm{A}$ affect the time series of annual precipitation, along with the discontinuity of the time series and its spatial distribution. They are compared with similar analyses of Automated Meteorological Data Acquisition System (AMeDAS) data which are considered to be most reliable.

\section{DATA AND METHOD}

We used R/A and AMeDAS data observed at every hour on the hour during January 1991 to December 2009 (19 years) since digital radars had been installed throughout Japan in 1991. Regarding AMeDAS, we used only the data whose station numbers remained unchanged during this period. The interannual variation of the spatial resolution of $\mathrm{R} / \mathrm{A}$ was described in the previous section. For creating

Received 16 March, 2011 Accepted 23 May, 2011 


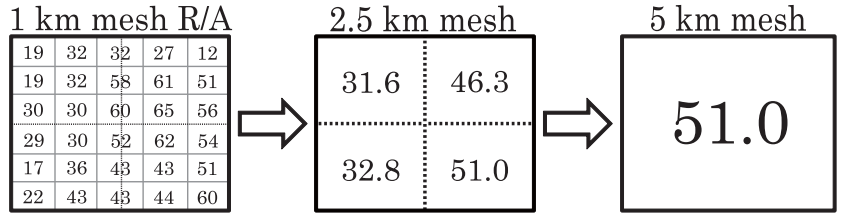

Spatial average Select the maximum value of $2.5 \mathrm{~km}$ mesh data

Figure 1. Method for converting ca. $1 \mathrm{~km}$ mesh R/A to ca. $5 \mathrm{~km}$ data via ca. $2.5 \mathrm{~km}$ data (modified after Deshimaru et al., 2009). Unit: $\mathrm{mm} / \mathrm{h}$. Data of the third column in the 1 $\mathrm{km}$ mesh R/A are respectively $32,58,60,52,43,43 \mathrm{~mm} / \mathrm{h}$. The representative area of the mesh in this column is half of that in the other columns (see text).

$5 \mathrm{~km}$ mesh data, we overlaid $2.5 \mathrm{~km}$ and/or $1 \mathrm{~km}$ data onto $5 \mathrm{~km}$ data. Then we adopted the following three methods.

I. The spatial average of $2.5 \mathrm{~km}$ mesh data or $1 \mathrm{~km}$ data was calculated. It was regarded as the representative value of $5 \mathrm{~km}$ mesh. This method was adopted in Kamiguchi et al. (2010, and personal communication).

II. The maximum of $2.5 \mathrm{~km}$ mesh data or $1 \mathrm{~km}$ data was selected. It was regarded as the representative value of $5 \mathrm{~km}$ mesh. This method was adopted in Tsuguchi and Kato (2010).

III. The method is displayed in Figure 1, as suggested by Nagata and Tsujimura (2006). JMA has adopted this method to convert $1 \mathrm{~km}$ mesh data to $5 \mathrm{~km}$ data. As for converting $2.5 \mathrm{~km}$ mesh data to $5 \mathrm{~km}$ data, this method is regarded as most appropriate.

The R/A data after April 2001 were respectively converted to $5 \mathrm{~km}$ mesh data using methods I-III presented above. As for 2001, we respectively attached the $5 \mathrm{~km}$ mesh data until March with those after April using methods I and II above, which resulted in the time series of two kinds. From April 2001 to December 2005, methods II and III are identical because the spatial resolution of R/A is $2.5 \mathrm{~km}$ during this period. Differences of methods II and III appear after January 2006.

The annual maximum and mean daily precipitation data were calculated for each mesh. Then, their spatial averages were calculated using $5 \mathrm{~km}$ meshes over the land, using the rasterized data of Digital Map 25000 (Map Image) issued by Geospatial Information Authority of Japan.

We applied the Wilcoxon test to several kinds of time series to detect abrupt changes. We also applied the homogeneity test proposed by Wijngaard et al. (2003) to the time series. It is composed of four tests using the statistics related to (1) standardized data, (2) summation of anomaly data, (3) summation of ranks, and (4) the relation between interannual variability and variance of the data. If null hypothesis (time series is not inhomogeneous) is rejected less than twice, the time series is regarded homogeneous and judged as "useful". In case the rejection is twice or larger than twice, it is respectively judged as "doubtful" or "suspect". We obtained thresholds of $n=19$ (1991-2009) by linear extrapolation of those for $n=20$ and $n=30$ of Tables III-VI in Wijngaard et al. (2003).
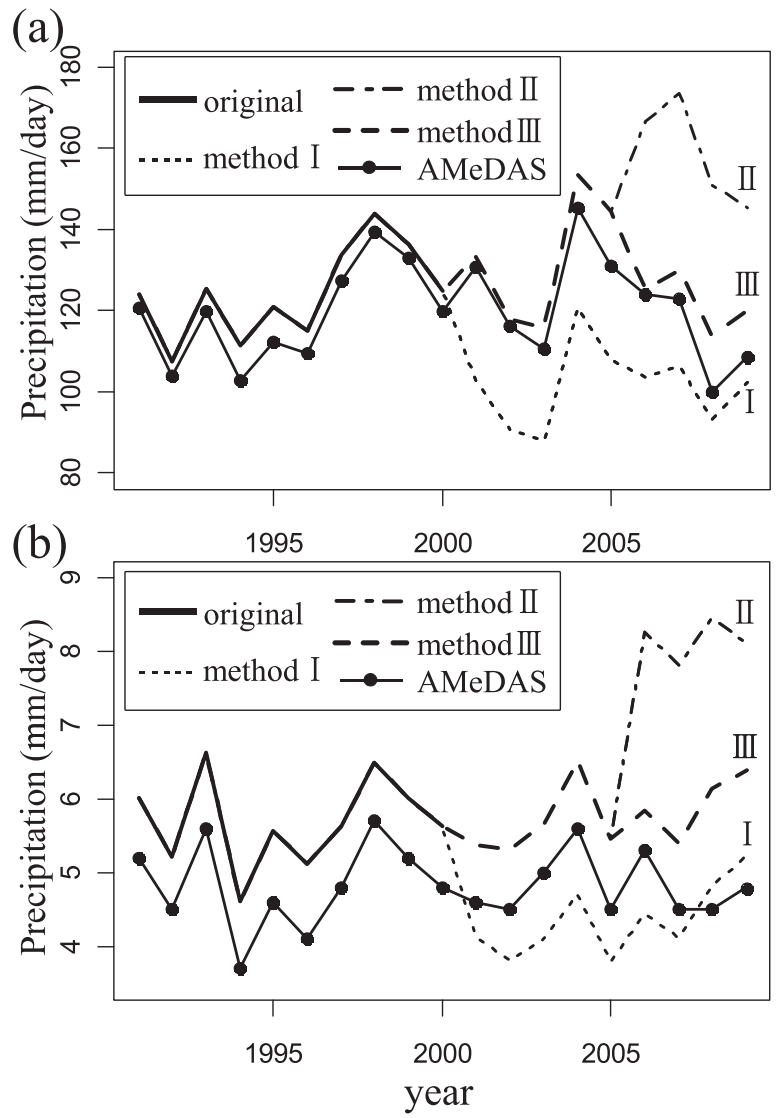

Figure 2. (a) Interannual variation of the annual maximum daily precipitation during 1991-2009. The legend "original" is the $5 \mathrm{~km}$ mesh data themselves until 2000. (b) Same as (a) but for the annual mean daily precipitation.

\section{RESULTS}

\section{Discontinuity and homogeneity of the time series}

Figure 2 presents the interannual variation of the annual maximum and mean daily precipitations. Differences of the three methods are readily apparent in Figure 2. Regarding method I, both the annual maximum and mean daily precipitations were apparently underestimated after 2001. The Wilcoxon test revealed that the difference between 1991-2000 and 2001-2009 was statistically significant at the $1 \%$ level both for Figures $2 \mathrm{a}$ and $2 \mathrm{~b}$. As for method III and AMeDAS data, we found no such discontinuities in 2000/2001.

Figure 2 also depicts differences of methods II, III, and AMeDAS data after 2006. Regarding method II, both the annual maximum and mean daily precipitations are overestimated after 2006. The Wilcoxon test revealed that the difference between 1991-2005 and 2006-2009 was statistically significant at the 5\% level for Figure 2a and 1\% level for Figure $2 b$, respectively. As for method III and AMeDAS data, we found no such discontinuities in 2005/ 2006.

The homogeneity test revealed that for the annual maximum daily precipitation (Figure $2 \mathrm{a}$ ), method III and AMeDAS data were regarded homogenous and judged as 'useful', whereas methods I and II were judged as 'suspect'. 
Related to the annual mean daily precipitation (Figure $2 b$ ), method III and AMeDAS data were also judged as 'useful', whereas methods II and I were respectively judged as 'doubtful' and 'suspect'.

In this case, AMeDAS data are the most reliable because they are point observations and are regarded homogeneous. Namely, method III is most reliable from a quantitative point of view.

\section{Spatial distribution of the discontinuity in 2000/2001}

Figure 3 displays the spatial distribution of the discontinuity in 2000/2001, which was apparent in the annual maximum daily precipitation. We respectively applied the Wilcoxon test to the time series of each mesh, as obtained using method I (Figure 3a), method III (Figure 3b), and AMeDAS data (Figure 3c). In Figure 3a, red meshes (statistically significant decrease after 2001 at the 1\% level) are distributed throughout Japan which form some regional clusters. However, neither Figure $3 \mathrm{~b}$ nor $3 \mathrm{c}$ shows such a spatial pattern, i.e., we don't find regional clusters as seen in Figure 3a. In Figure 3c, precipitation increased at a part of the Tohoku District, especially at the Oga Peninsula, in the southwestern part of Shikoku Island, and in the eastern part of Kyushu Island. Contrarily, precipitation decreased at western part of Hokkaido and Shikoku Island. It is difficult to say that Figure $3 b$ is similar to Figure $3 c$, however, the spatial pattern of Figure $3 \mathrm{a}$ is not found in Figure $3 \mathrm{c}$.

The difference is more conspicuous in Figure 4. The decrease of the annual mean daily precipitation after 2001 is apparent all over Japan in Figure 4a, although such a spatial pattern is not obvious in Figures $4 \mathrm{~b}$ and $4 \mathrm{c}$. In Figure $4 \mathrm{c}$, precipitation increased at southwestern part of the Kanto District, the Izu Peninsula, and the Sea of Japan side of Hyogo Prefecture. In contrast, precipitation decreased at the central part of Hokkaido. Here, we should stress that the systematic decrease of precipitation diplayed in Figure $4 \mathrm{a}$ is not apparent in Figure 4c. (a)

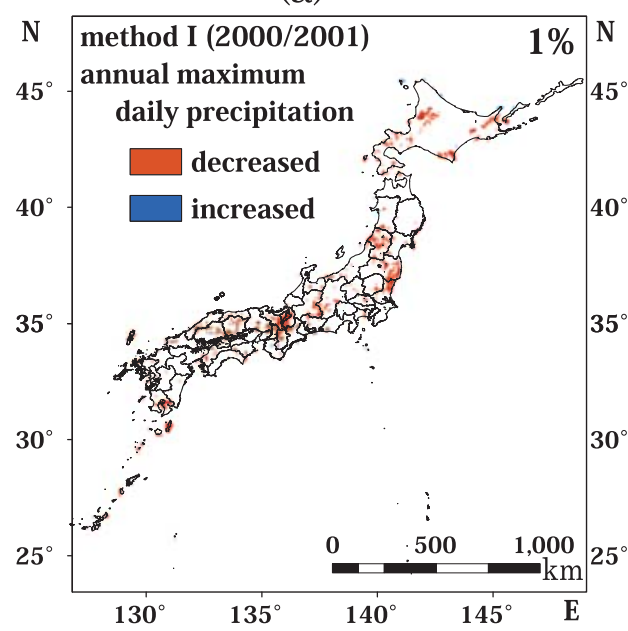

(b)

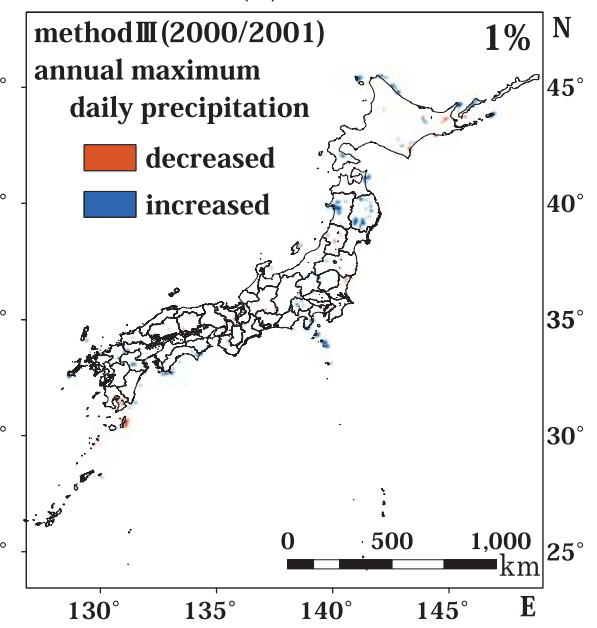

(c)

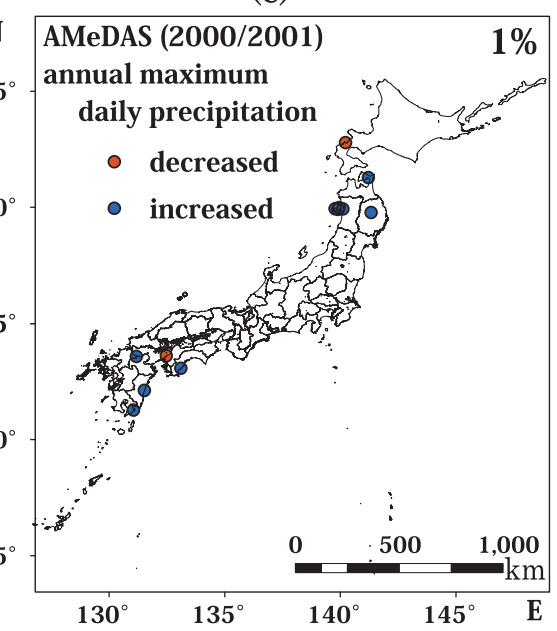

Figure 3. (a) Discontinuity of the annual maximum daily precipitation between 1991-2000 and 2001-2009, calculated from R/A using method I. Red/blue meshes display that statistically significant decreases/increases were detected for 2001-2009 at the $1 \%$ level by the Wilcoxon test. (b) Same as (a) but for method III. (c) Same as (a) but for AMeDAS data.

(a)

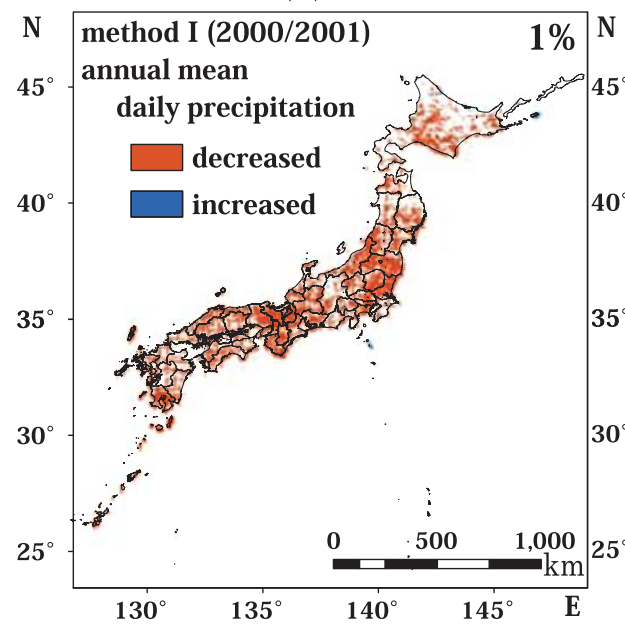

(b)

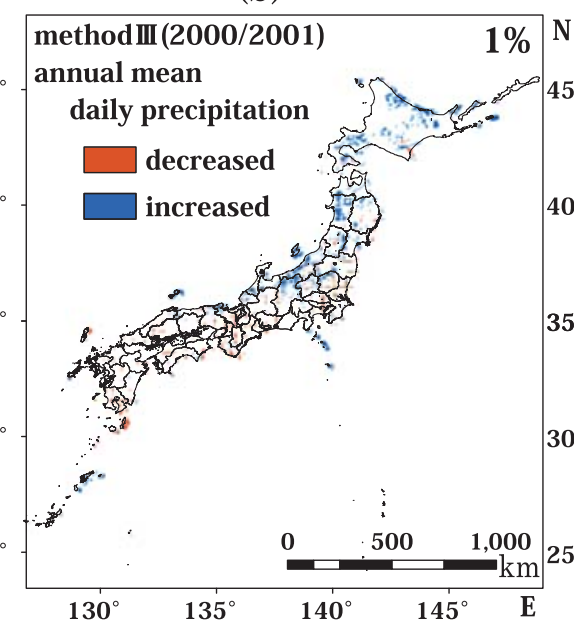

(c)

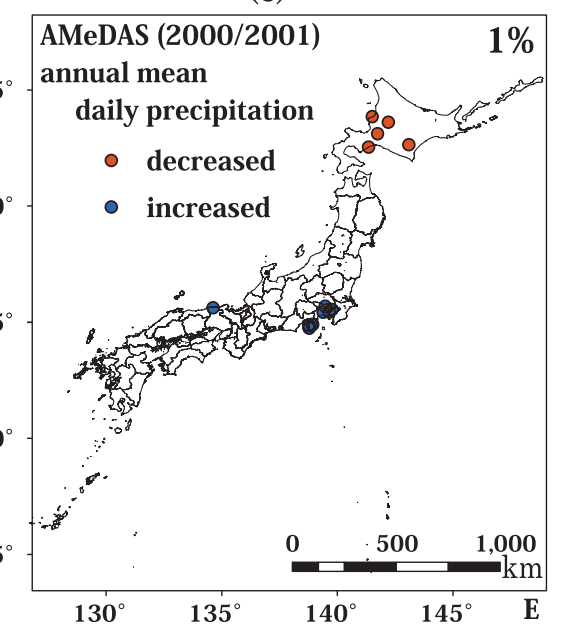

Figure 4. Same as Figure 3 but for the annual mean daily precipitation. 
Spatial distribution of the discontinuity in 2005/2006

Figure 5 is same as Figure 3 but for the discontinuity in $2005 / 2006$. The Wilcoxon test was respectively applied to the data obtained using method II (Figure 5a), method III (Figure 5b), and AMeDAS data (Figure 5c). In Figure $5 \mathrm{a}$, only blue meshes (statistically significant increase after 2006 at the 1\% level) are distributed throughout Japan which form some regional clusters such as in Figure 3a. However, Figures $5 \mathrm{~b}$ and $5 \mathrm{c}$ show no such spatial pattern. In Figure $5 \mathrm{c}$, precipitation increased at a part of the Tohoku District and Kyushu Island, although it decreased at the Pacific side of Hokkaido. It is difficult to say that Figure $5 \mathrm{~b}$ resembles Figure $5 \mathrm{c}$, however, the spatial pattern of Figure $5 \mathrm{a}$ is not obvious in Figure $5 \mathrm{c}$.

The difference is more conspicuous in Figure 6. The increase of the annual mean daily precipitation after 2006 is apparent throughout Japan in Figure 6a, although such a spatial pattern is not found in Figures $6 \mathrm{~b}$ and $6 \mathrm{c}$. In Figure $6 \mathrm{c}$, precipitation decreased at some parts of Hokkaido which is not reproduced by both Figures $6 \mathrm{a}$ and $6 \mathrm{~b}$. However, it is not too much to say that the systematic increase of precipitation depicted in Figure 6a is not found in Figure 6c.

\section{DISCUSSION AND CONCLUSION}

Based on the results obtained, the present study quantitatively demonstrated that the different methods for creating $5 \mathrm{~km}$ mesh R/A significantly affected its interannual variation. In comparison with data obtained before 2000 and 2005, R/A shows discontinuity depending on the conversion methods because $2.5 \mathrm{~km}$ mesh R/A and $1 \mathrm{~km} \mathrm{R} / \mathrm{A}$ can capture smaller-scale precipitation which results in greater differ- (a)

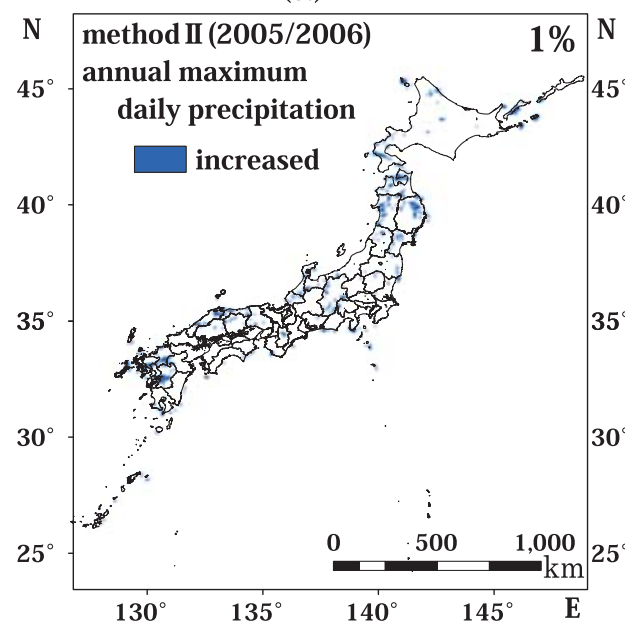

(b)

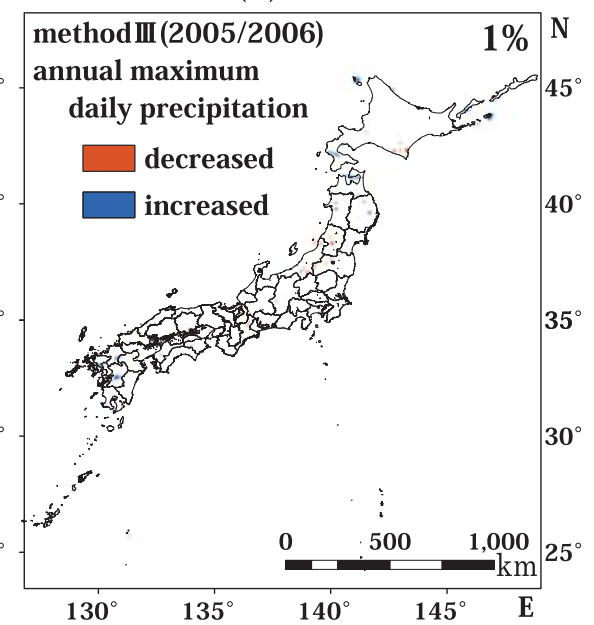

(c)

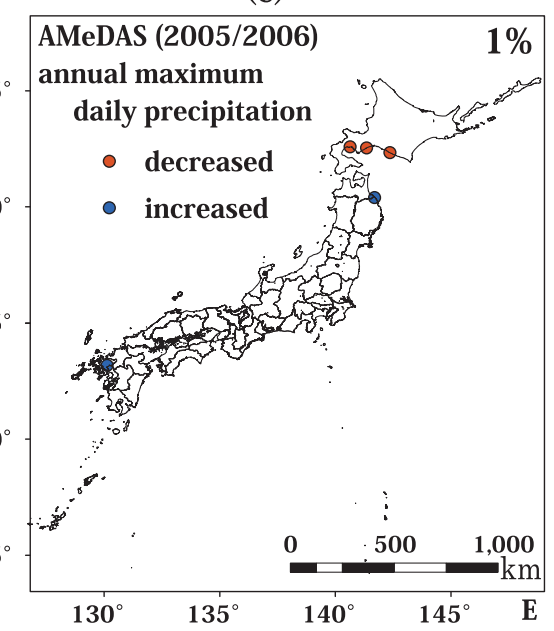

Figure 5. (a) Discontinuity of the annual maximum daily precipitation between 1991-2005 and 2006-2009, calculated from R/A using method II. Blue meshes display that statistically significant increases were detected for 2006-2009 at the 1\% level by the Wilcoxon test. (b) Same as (a) but for method III. Red meshes display that statistically significant decreases were detected for 2006-2009 at the 1\% level by the Wilcoxon test. (c) Same as (b) but for AMeDAS data.

(a)

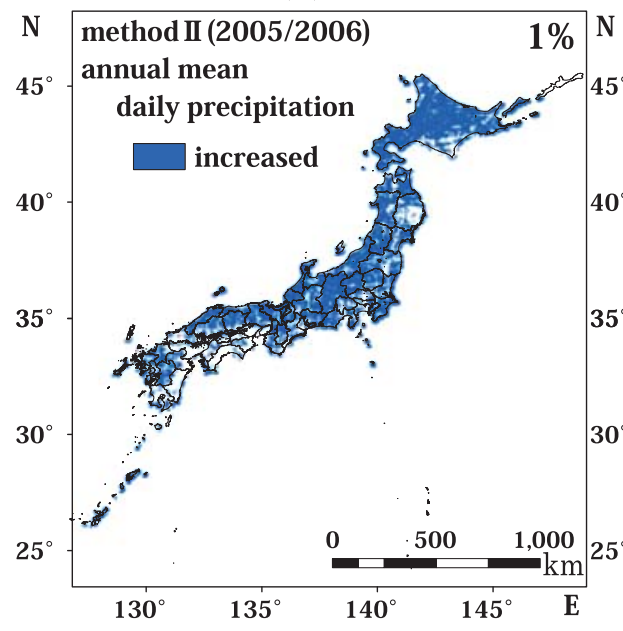

(b)

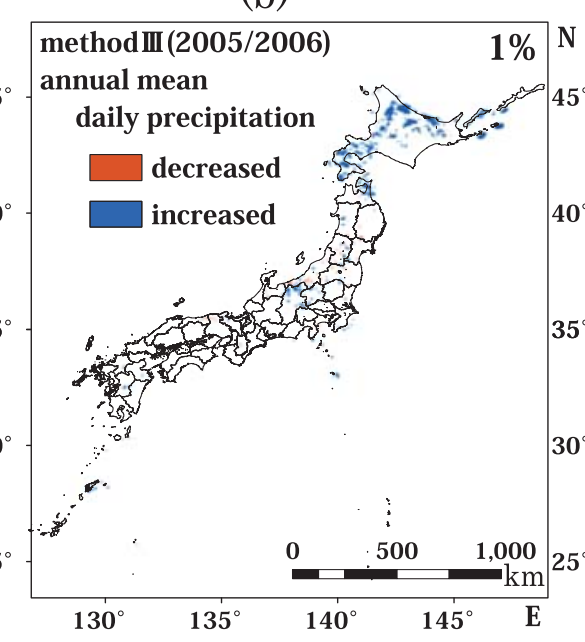

(c)

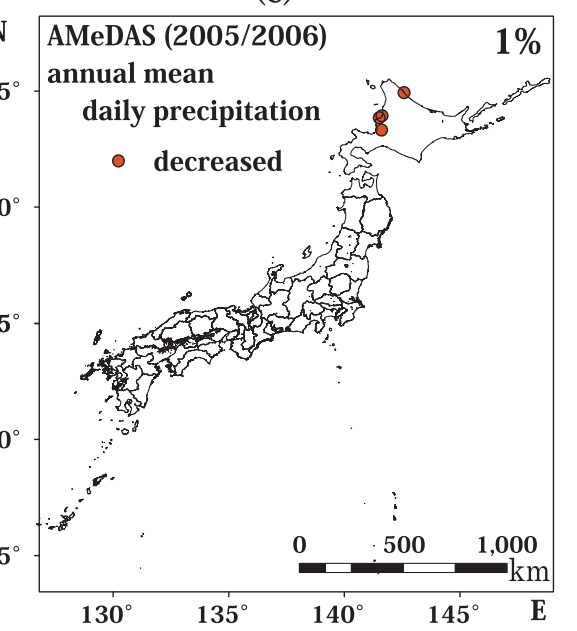

Figure 6. Same as Figure 5 but for the annual mean daily precipitation. 
ences of precipitation among meshes. For creating $5 \mathrm{~km}$ mesh data, method III is most appropriate because the time series created by method III was regarded homogeneous and judged as 'useful'. Furthermore, we found few discontinuities in 2000/2001 and 2005/2006 related to the spatial distribution. Method III is also supported by the fact that JMA advises the creation of $5 \mathrm{~km}$ mesh data using this method (Nagata and Tsujimura, 2006). However, this method is not perfect, i.e., it is still insufficient for capturing the characteristics of AMeDAS data (Figures 4 and 6).

Although there is still room for further analyses, this study quantitatively confirmed the validity of method III. In conclusion, we should use method III to create a longterm $\mathrm{R} / \mathrm{A}$ to study the interannual variation of $\mathrm{R} / \mathrm{A}$.

\section{ACKNOWLEDGEMENTS}

The authors are grateful to Mr. K. Okada of JMA for providing invaluable information related to $\mathrm{R} / \mathrm{A}$. Comments by the editor, Dr. Y. Tachikawa of Kyoto University and two anonymous reviewers are highly appreciated. This study was partially supported by a Grant-in-Aid for JSPS Research Fellows, MEXT (No. 20-6594), the Asahi Glass Foundation, along with the River Fund in charge of the Foundation of River and Watershed Environment Management, Japan (No. 22-1213-004).

\section{REFERENCES}

Deshimaru T, Takeda Y, Ohta T, Yokota S. 2009. New warnings of heavy rainfalls and severe floods. Training Text of Quantitative Forecast in 2008: 1-30 (in Japanese).

Kamiguchi K, Arakawa O, Kitoh A, Yatagai A, Hamada A, Yasutomi N. 2010. Development of APHRO_JP, the first Japanese high-resolution daily precipitation product for more than 100 years. Hydrological Research Letters 4: 60-64. doi:10.3178/HRL.4.60.

Nagata K, Tsujimura Y. 2006. Characteristics of Radar/RaingaugeAnalyzed Precipitation and short-range precipitation forecast along with notices on their usage. Training Text of Quantitative Forecast in 2006: 9-24 (in Japanese).

Okada K. 2007. Current state of disaster generation risk forecast by Soil Water Index. Tsuchi-to-kiso 55: 4-6 (in Japanese).

Okada K, Makihara Y, Shimpo A, Nagata K, Kunitsugu M, Saito K. 2001. Soil Water Index. Tenki 48: 349-356 (in Japanese).

Tsuguchi H, Kato T. 2010. Objective method for detecting heavy rainfall events. Abstracts of the Meteorological Society of Japan 2010 Spring Meeting 97: 55 (in Japanese).

Wijngaard JB, Klein Tank AMG, Können GP. 2003. Homogeneity of 20th century European daily temperature and precipitation series. International Journal of Climatology 23: 679-692. doi:10.1002/joc.906. 